\title{
Nota sobre a recepção de Rilke na lírica brasileira do segundo pós-guerra
}

\author{
Note about the reception of Rilke in the Brazilian lyric of the second post-war
}

\author{
VAGNER CAMILO \\ Universidade de São Paulo (USP)
}

-

\begin{abstract}
Resumo: O presente artigo integra um estudo mais longo (CAMILO, 2013) sobre a conversão neoclássica que marcou tanto a lírica de nomes representativos do Modernismo brasileiro (como Drummond, Jorge de Lima, Murilo Mendes e Augusto Meyer) nos anos 1940 e 1950, quanto a poesia da então emergente geração de 45. Para essa conversão, muito contribuiu as concepções sobre o poético de nomes como Eliot, Valéry e Rilke. Interessa aqui discutir alguns aspectos da recepção deste último apenas, partindo do que já inventariou a crítica a esse respeito.
\end{abstract}

Palavras-chave: Rilke; Neoclassicismo; Lírica brasileira moderna; Geração de 45

\begin{abstract}
This article is part of a longer study (CAMILO, 2013) on the neoclassical conversion that marked both the lyric poetry of representative poets of Brazilian Modernism (such as Drummond, Jorge de Lima, Murilo Mendes, and Augusto Meyer) in the 1940s and 1950s, and the poetry of the emerging geração de 45 (generation of 45). The works and poetic conceptions of Eliot, Valéry, and Rilke contributed decisively for this conversion. Here, it is important to discuss only a few aspects of the reception of Rilke's poetry and ideas from what critics have already cataloged.
\end{abstract}

Keywords: Rilke; Neoclassicismo; Modern Brazilian lyric; Geração de 45 (Generation of 45)

Um primeiro rastreamento da recepção poética de Rilke no Brasil e em Portugal foi realizado por Arnaldo Saraiva, mas sem chegar a promover o confronto de tais apropriações em vernáculo com os originais. O estudo dessa recepção, no caso brasileiro, está ainda à espera de um trabalho de fôlego equiparável ao que legou Maria António Hörster no espantoso inventário e análise detida do rilkeanismo em Portugal. Trabalho esse, aliás, altamente relevante para nós, quando se considera que muitas das traduções e apropriações lusitanas talvez tenham servido de referência aos poetas brasileiros das décadas de 1940 e 1950. Isso sem esquecer que um dos primeiros comentaristas de Rilke em Portugal, João Gaspar Simões, era muito próximo dos poetas brasileiros de então, tendo escrito artigos importantes sobre grandes nomes como Drummond e Jorge de Lima, além de colaborar para os principais veículos de divulgação da geração de 45 (HÖRSTER, p.789ss). Obviamente, Hörster não está interessada na atuação de Gaspar Simões junto aos brasileiros, mas examina e reproduz em apêndice as contribuições do crítico português para a divulgação do rilkeanismo em Portugal, conforme se vê no capítulo dedicado às "Primeiras referências a Cartas a um jovem poeta" (HÖRSTER, p. 108-115 e 439-448). Entre nós, Simões é um guia importantíssimo para o mapeamento das discussões do período, já que, em mais de um momento, ele advertiu para os riscos da leitura tendenciosa que se fazia à época não só de Rilke, como também de Eliot.

Muitas das apropriações de Rilke promovidas pelos poetas brasileiros não se beneficiaram do acesso direto ao alemão, valendo-se, com frequência, de traduções francesas e em vernáculo - no caso, as referidas traduções de Portugal. Hörster também trata de arrolar, em apêndice, as traduções francesas, além do exame detido, é claro, das versões portuguesas, que se iniciaram em fins dos anos 1930, pelas mãos competentíssimas de Paulo Quintela (HÖRSTER, p. 127ss e 719ss).

Por ora, do que é possível entrever da voga desse rilkeanismo no pós-guerra, pode-se afirmar que o diálogo deu-se, no Brasil, em torno do orfismo e da retomada de formas clássicas como a elegia e o soneto, privilegiando, para tanto, apenas uma dada parcela da obra rilkeana, a de inflexão metafísica, representada pelos Sonetos a 
Orfeu e As elegias de Duíno, em detrimento de outra, a da experimentação mais radical dos poemas-coisa (Dinggedichte) recolhidos em Novos poemas (CAMPOS, p. 17-20). Assim, como notou Augusto de Campos, promovia-se, aqui também, o que Paul de Man denominou, em outro contexto, de "interpretação messiânica" da lírica rilkeana.

Como bem explica o autor de Alegorias da leitura, essa dimensão messiânica da obra do poeta austríaco e o "poder curativo" a ela atribuído são os responsáveis pela recepção fervorosa e pelo grande sucesso alcançados por Rilke além das fronteiras do mundo de língua alemã, a despeito das dificuldades impostas pelo hermetismo característico de sua poesia, que resiste à tradução, pelos temas intimíssimos e pelo discurso oblíquo:

Muitos o leram como se ele se dirigisse às partes mais secretas de seus íntimos, revelando profundezas de que eles mal suspeitavam ou permitindo-lhes compartilhar provações que o poeta ajudou a compreender e superar. [...] Rilke parece ser dotado do poder curativo daqueles que abrem acesso às camadas ocultas de nossa consciência, ou a uma delicadeza de emoção que reflete, para aqueles capazes de perceber suas nuances, a imagem confortadora de sua própria solicitude. O próprio Rilke muitas vezes jogou com a ambiguidade de uma relação de dupla face que mantinha com os outros, deixando em suspenso a definição de qual dos dois, o poeta ou seu leitor, dependia do outro para nutrir sua própria força. [...] Uma forma de decoro poético, em si uma mistura de cuidado e reserva genuína, mantém as imagens violentas à distância, e impede que adquiram uma presença forte o bastante para desfazer a ficção ou deslocar a linguagem. [...] Além do brilho das cenas, a obra de Rilke ousa afirmar e prometer, como poucas, uma forma de salvação existencial que ocorreria na poesia e por meio dela. Raros poetas e pensadores de nosso século ousaram ir tão longe em suas afirmações, especialmente naquelas que se recusam a ancorar-se em certezas filosóficas e teológicas estabelecidas, ou a recorrer aos imperativos éticos que poderiam conduzir diretamente a modos de ação. [...] Pode-se entender portanto que Rilke não só reivindica o direito de afirmar sua própria salvação, mas também o de impô-la, por assim dizer, aos outros. O modo imperativo que frequentemente aparece em sua poesia [...] não é dirigido apenas a si mesmo, mas pede a aquiescência de seu leitor. A exortação se enraíza numa autoridade confirmada pela possibilidade de sua existência poética. Longe de colocar essa certeza em risco, a insistência nos temas negativos assegura a sua veracidade. Uma promessa garantida com demasiada facilidade seria suspeita e não convincente, mas uma promessa de salvação que só poderia ser merecida através de trabalho e sacrifício infinitos, no sofrimento, na renúncia e na morte, é outra coisa. Só podemos começar a entender a poesia de Rilke se estivermos dispostos a assumir essa convicção (DE MAN, p. 38-41).
É essa forma de salvação na e pela poesia, a autoridade confirmada pela possibilidade da existência poética de Rilke e seu "decoro poético", enfim, que a geração de 45 acalentou como ideal, justamente num momento de acentuada crise do gênero, de que tratei em outro momento (CAMILO, 2013). Tais atributos que o poeta alemão parece encarnar são, em suma, os do mito órfico, que os poetas de 45 , cantando o poder restaurador e civilizador do mito, buscaram também reivindicar para si, inspirados pelo exemplo do autor de Sonetos a Orfeu.

Ainda sobre a eleição da parcela da obra de Rilke predominante entre nós, representada pelos Sonetos a Orfeu e Elegias de Duíno, vale citar as observações de Saraiva ao estabelecer o confronto com a preferência dos portugueses na mesma época:

[...] o grupo da "Geração de 45", que edita a revista sintomaticamente denominada Orfeu (sintomaticamente: pela conotação com o personagem mítico, sim, mas também com a revista do modernismo português e com o título de um livro de Rilke), faz publicar nesta [...] a tradução, não assinada, de uma "carta a um jovem poeta"; sob o pseudônimo Marcelo Sena, Cristiano Martins atreve-se a publicar um livro sobre Rilke, o Poeta e a Poesia (1949); e Vinicius de Moraes, que traduziu uma das elegias de Duíno, compôs a sua "Imitação de Rilke" e escreveu o "Soneto do Só ou Parábola de Malte Laurids Brigge", como mais tarde viria a escrever a crônica "Relendo Rilke", que incluiu no livro de 1962 Para Viver um Grande Amor [...]. A publicação de tantos textos de Rilke e sobre Rilke acompanha naturalmente a influência da sua obra na de portugueses e brasileiros. Essa influência tem sido unanimemente apontada de um lado e outro do Atlântico - e vai de temas ou motivos, como o angelismo e as rosas, a formas e a modalidades enunciativas, como as típicas do soneto e da elegia [...] no Brasil, onde essa influência é apontada por vários críticos e historiadores da literatura [...] e onde Milton de Godoy Campos, que organizou uma Antologia Poética da Geração de 45 [...], pode afirmar: "Por influência de Rilke e de Fernando Pessoa o hermetismo se faz presente em bom número de poetas, ou aparece esporadicamente em outros" [...]. Todavia, a acreditarmos em Haroldo de Campos, os poetas brasileiros dos anos 40 terão preferido o Rilke das Elegias e dos Sonetos a Orfeu [...], coisa que decerto não aconteceu com os portugueses, mais sensíveis, parece, aos acentos dos Novos Poemas ou até do Livro das Imagens e do Livro de Horas. Assim, não admira que os brasileiros cultivem abundantemente, a partir dos anos 40, o soneto - cuja defesa chegou a ser feita na revista Orfeu; de tal modo que é a composição exclusiva de livros de poetas de 45, como Ledo Ivo, autor de Acontecimento do Soneto (1948), Geir Campos, autor de Coroa de Sonetos (1953), Afonso Félix de Sousa, Marcos Konder Reis, Domingos Carvalho da Silva e outros, que terão contagiado poetas mais velhos como 
Jorge de Lima, autor de um Livro de sonetos (1949), ou como o próprio Carlos Drummond de Andrade, que em certo momento chegara a ridicularizar tal forma e que a pratica numerosamente em livros dos fins de 40 e inícios de 50, num dos quais, Claro Enigma, também falou no "sentimento de um achado precioso como o de Catarina Kippenberg aos pés de Rilke" [...]; ou como Vinicius de Moraes, autor também de um Livro de Sonetos (1957), em que figura exactamente o "Soneto do Só ou Parábola de Malte Laurids Brigge", datado de 1946 [...] Por outro lado a elegia, já cultivada por Cecília Meireles na década de 30 ("Elegia", 193337), e na década de 40 abundantemente produzida por poetas como Péricles Eugénio da Silva Ramos, autor de «Elegia à lua de olhos de prata» (1941), que é dada [...] como o poema que marca a passagem para um novo processo poético no Brasil; Vinicius de Moraes, autor de Cinco Elegias (1943); Ledo Ivo, autor de Ode e Elegia (1945); Dantas Mota, autor de Elegias do País das Gerais (1946); Jose Paulo Moreira da Fonseca, autor de Elegia Diurna (1947); Mauro Mota, autor de Elegias, publicadas já em 1952, etc. [...] De resto, os portugueses da década de 40 também não farão as concessões que os brasileiros fazem às rimas ou às sonoridades claras e densas e à metrificação rigorosa. Muito voltados para a secular lírica portuguesa, os poetas brasileiros insistem nos temas e motivos tradicionais, que são também rilkeanos, do amor, da solidão, da morte, da infância, das estações, dos frutos, mas sem os revalorizarem mais do que no apuro métrico e rítmico e no brilhantismo imagístico. Convirá não esquecer [...] a excepção notável de João Cabral de Melo Neto que à primeira vista parece pouco sensível a Rilke, mas que acusa a sua leitura em poemas como "Estudos para uma bailadora andaluza", o qual não pode deixar de evocar a "Bailarina espanhola". Acontece apenas que, ao contrário dos seus companheiros [...], João Cabral foi mais seduzido exactamente pelos Novos Poemas, a que pertence a "Bailarina". É, aliás, isto mesmo que ele diz no livro Museu de Tudo [...] e no poema exactamente intitulado "Rilke nos Novos Poemas" (SARAIVA, p. 17-20).

Apesar de muito longo, a citação do trecho em questão é necessária pelo que sintetiza da recepção rilkeana no período de que nos ocupamos aqui. Podemos acrescer, ao rápido inventário promovido por Saraiva, a repercussão rilkeana em outros números da revista $\mathrm{Orfeu}$, pensando em artigos e polêmicas sobre o poético em que o nome e as concepções estéticas do poeta austríaco vêm à baila. Assim ocorre com o artigo de Lins do Rego, "Ainda os novos", em que ressalta o caráter renovador da revista dos poetas de 45 , buscando "desinsular" e agregar os bons escritores brasileiros, além de reivindicar uma arte e uma crítica conscientes, citando trechos das cartas de Rilke para defender uma poesia calcada na vida e na experiência do poeta (Orfeu, n. 3, outono de 1948, p. 84). Outro número traz artigo polêmico de Paulo Mendes Campos, em que condena certa vertente da crítica que tende a ater-se apenas ao "pensamento" dos poetas (notadamente os herméticos como Rilke) em detrimento da "expressão poética” (Orfeu, n. 1, primavera de 1947, p.9).

Se estendêssemos o inventário a outros periódicos da época, poderíamos dimensionar melhor a repercussão do rilkeanismo no período. É o caso da revista Joaquim, que publicou dois trechos de cartas de Rilke no n. 15 (nov 1947) e "Fragmentos das Elegias de Duíno" no n. 7 (dez 1946). É o caso, ainda, do Suplemento Pensamento e Arte, do jornal Correio paulistano, à frente do qual também atuaram, editorialmente, membros da geração de 45 e no qual se publicou, no número de 25/08/1951, as "Odes de Edgar Braga”, com apresentação de Domingos Carvalho da Silva atestando a influência, entre outros, de Rilke.

Em meio ao orfismo dominante de que fala Saraiva, levando vários dos poetas de 45 , bem como os modernistas neoclássicos, à reescrita do mito, valeria destacar dois momentos em que o diálogo com o Rilke de Sonetos a Orfeu é flagrante.

O primeiro deles vem representado pelo " 3 o Soneto a Orfeu", incluído nas Elegias de Mauro Mota, livro editado pelo Jornal de Letras, em 1952, com capa de Santa Rosa e ilustrações de Farnese, além do prefácio de Álvaro Lins:

\section{$3^{\circ}$ Soneto a Orfeu}

Boca de fonte, ó boca generosa, parece que interrompes o teu canto quando o cântaro se interpõe. Rainer M. Rilke

Ó fonte, fonte solitária, cantas.

Ouço o teu canto de alegria nesta tarde de abril igual às outras tantas tardes que se passaram na floresta.

Aos sátiros e ninfas ouvir resta a canção misteriosa das gargantas de pedra. A natureza faz a sesta, adormecem os pássaros e as plantas.

$\mathrm{O}$ teu canto de amor não parto ao meio se ao cântaro te junto, fonte, e quando o retiro, da voz líquida cheio.

Pouco importa que esta água seja pouca, porque se ela jorrou da tua boca, no cântaro que levo vai cantando (MOTA, p. 49).

Como se vê, o próprio Mota trata de explicitar, na epígrafe, a fonte rilkeana em que foi beber diretamente: trata-se do famoso soneto II, 15 sobre a "doadora bocachafariz”, na tradução de Augusto de Campos, que diz ser este um dos mais sucintos e substantivos dos Sonetos a Orfeu, infundindo "corpus às perquirições metafísicas". (CAMPOS, p. 32). Por essa dimensão mais substantiva, dada pela materialidade da fonte de que parte a reflexão 
filosófica típica do livro, o poema em questão tenderia a se aproximar da objetualidade característica dos Dinggedichte. Não por acaso, esse soneto dialoga de perto com "A fonte romana", que, ainda de acordo com Campos, é "um dos sonetos objetuais mais característicos dos Novos poemas" (CAMPOS, p. 32). Nesse sentido, embora continue fiel à tendência de sua geração, afeita ao Rilke mais filosofante dos Sonetos a Orfeu, Mota parece flertar com a outra vertente rilkeana, então menos celebrada entre nós, ao eleger o soneto mais próximo dos poemas-coisa dos Novos poemas. A questão é saber de qual dessas duas vertentes se aproxima o " 3 o Soneto a Orfeu", cujo título instiga, porque parece sugerir a existência de dois outros que, entretanto, não consta das Elegias...

Glosando o mote dado pelo terceto final do soneto rilkeano, Mota propõe outro desfecho: a persistência do canto da água da fonte lá onde ele é interrompido pela interposição do cântaro. Explorando a associação homofônica entre canto, cantar e cântaro, o poema de Mota pode ser lido metalinguisticamente: sua poesia é o modesto cântaro que mantém o fluxo contínuo da água imemorial, vinda de longe, do fundo dos tempos, por entre tumbas, descendo do Apenino e, ininterruptamente, jorrando da fonte rilkeana. Disse modesto porque, embora "cheio de voz líquida", a estrofe final do soneto de Mota afirma, paradoxalmente, que a água retida no cântaro que eu lírico leva é "pouca", de todo modo suficiente para seguir "cantando".

O emprego abundante dos enjambements (exceto no último terceto, que trata do líquido retido no cântaro), ao fazer desbordar ou transbordar os sintagmas de um verso a outro, talvez esteja em associação mimética com esse fluxo contínuo. Isso porque, como se sabe, o enjambement, ao invés da habitual pausa descendente final, impõe uma entonação ascendente, sem pausa, para indicar a continuidade da frase - o que vale dizer, a persistência da fluidez do canto.

O segundo poema de inspiração claramente rilkeana é "Esboço para Orfeu", publicado no fecho da Elegia diurna, de José Paulo Moreira da Fonseca. Retomo aqui apenas a $1 \stackrel{\text { a }}{\text { estrofe: }}$

Ergue-se um canto - o mundo renascido vive tua forma -

Aquele templo antigo, o mar entre as penhas ou jovem mulher obscura,

Tudo como se fora pedra em friso

Diurnamente transparecendo o ritmo de nosso hálito -

Ó momento consolo num grande anseio

E talvez torne a paz entre a terra e o íntimo -

Efêmero refazer-se de perdida essência!

(FONSECA, p. 99-100)
$\mathrm{Na}$ aproximação entre o canto e a construção ou o erguer de um templo, o autor de Elegia diurna deve ter-se inspirado na só em Rilke, mas também em Valéry. Já se examinou detidamente a estreita similaridade entre o primeiro dos Sonetos a Orfeu de Rilke (cujos versos iniciais dizem: "Um deus pode. Mas como erguer do solo, / na estreita lira, o canto de uma vida?" (CAMPOS, p. 151)) e o soneto "Orfeu" de Valéry, notadamente a imagem afim de um templo erigido por força do canto órfico. Judith Ryan estende, ainda, essa similaridade ao texto valéryano "O paradoxo sobre o arquiteto", que contem a primeira versão do soneto e no qual a civilização será "salva da decadência por um músico-arquiteto que restaurará a arte a seu lugar de direito". O soneto rilkeano celebra uma similar revalorização da arte. Essa mesma dimensão celebratória do modelo rilkeano, a respeito dos poderes do poeta encarnadas por Orfeu, tão presente nos poetas de 45, comparece também no "Orfeu" do Augusto Meyer dos Últimos poemas que se alinha a outros modernistas reclassicizados do período (MEYER, p.255). O mesmo Meyer que, em estudo posterior reunido em $A$ forma secreta, viria a falar do "mito Rilke".

Voltando ainda ao longo excerto do crítico português, é interessante a divergência sinalizada por Saraiva a respeito de João Cabral em relação à sua geração ao se apropriar da dimensão mais experimental, substantiva, concreta do legado rilkeano representada pela poesiacoisa de Novos poemas, num processo, como diz Campos, de "desegotização da lírica", muito afinada com a antilira do nosso poeta-engenheiro. Assim, ao invés do angelismo dominante, a opção pela materialidade da pantera; ao invés do lirismo e do teor confessional, a precisão e a "inconfissão", alcançando ainda assim a possibilidade do gozo ("incapaz de não gozar"), "mas sem onanismo", conforme dizem os versos cabralinos (MELO NETO, p.395). Cabral seria logo seguido, nessa divergência, pelos concretistas, já nos livros iniciais, concebidos ainda dentro do contexto poético dominado pelos poetas de 45 , a considerar o que alega Augusto de Campos (p. 26-27). Se em seu livro de estreia, Auto do possesso (1950), Haroldo de Campos recorria a uma epígrafe rilkeana ("Dize-me, Poeta, que fazes? - Eu celebro.”) não tão destoante do que a geração de 45 preferia eleger na obra do poeta austríaco, Décio Pignatari viria zombar violentamente essa eleição num poema de 1952, "Bufoneria Brasiliensis 1 - O poeta Virgem", cujos versos irreverentes dizem:

\footnotetext{
"Nessa efeméride, entreabrindo a burra

Onde se enlura, o poeta estoura:

"Mulheres, Rilke, esses bijus de um níquel!"

- e se emascula (PIGNATARI, p. 74).
} 
Vale, todavia, duas considerações com relação ao inventário proposto por Saraiva e complementado pelo presente artigo.

A primeira delas diz respeito à atribuição generalizada e indiscriminada do soneto e da elegia praticados pelos poetas brasileiros dos anos 1940 e 1950 a essa influência rilkeana, segundo parece sugerir o estudo do crítico português. Não creio que se possa tomar, sem mais, tal filiação no caso de alguns nomes do período. Por exemplo, é difícil sustentar a inspiração rilkeana no sopro de renovação de formas, linguagem, temas e motivos trazido pelas Cinco elegias de Vinícius de Moraes, marco na trajetória do poeta carioca em busca de uma sintaxe própria, que levou o Drummond de $A$ rosa do povo a saudá-lo como "poeta-irmão", justamente pela sua mais "límpida elegia" - referência segura a última delas, com toda a sua liberdade de criação neológica, seu bilinguismo (fundindo português e inglês) e a disposição gráfica de palavras e os versos, mimetizando os telhados (roofs) do Chelsea londrino, entre outros aspectos.

\section{A ÚLTIMA ELEGIA}

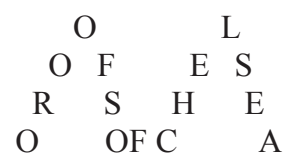

Greenish, newish roofs of Chelsea Onde, merencórios, toutinegram rouxinóis Forlornando baladas para nunca mais! Ó imortal landscape no anticlímax da aurora! ô joy for ever!

Na hora da nossa morte et nunc et semper $\mathrm{Na}$ minha vida em lágrimas! uer ar iú

Ó fenesuites, calmo atlas do fog Impassévido devorador das esterlúridas? Darling, darkling I listen... "... it is, my soul, it is

Her gracious self...” murmura adormecida

É meu nome!... (MORAES, 2001, p. 80).

Isso mesmo tendo Vinícius traduzido Rilke e composto poemas e crônica expressamente referidos ao autor dos Cadernos de Malte Laurids Brigge em outros momentos de sua obra.

De igual modo, é preciso cautela ao supor que o autor de Sonetos a Orfeu tenha sido referência para a retomada da forma fixa nos termos em que é praticada por Jorge de Lima no Livro dos sonetos ...

Idêntico cuidado é requerido no caso do citado Dantas Mota e suas Elegias do País das Gerais, tão celebradas por Drummond - que respondeu pela introdução da edição definitiva da obra desse poeta de Aiuruoca - e tão tributárias do legado poético do itabirano, entre outras coisas pelo enraizamento na realidade histórica mineira. Difícil reconhecer qualquer afinidade na sua concepção de elegia e na matéria histórico-social de que se alimentam seus versos - entre outras coisas, dedicados à realidade das populações ribeirinhas do Rio São Francisco - e a visada universalizante, alheia a todo horizonte sóciopolítico mais imediato, que define o teor das Elegias de Duíno, pautadas pelos temas e motivos tradicionais que o próprio Saraiva trata de arrolar no excerto reproduzido.

Pode-se dizer o mesmo de um poema posterior, por longo tempo inédito, de Dantas Mota, que não chega a ser citado por Saraiva, mas sobre o qual vale, já de antemão, advertir. Trata-se de Guaicurus, que traz como subtítulo: Cântico do porta-estandarte Dantas Mota em favor do seu doce, terno, casto e puro país dos Guaicurus ou, então, BHorizonte nas suas décadas de 33 a..., depois de Cristo. Embora o subtítulo pareça sugerir certa lembrança do famoso escrito de juventude de Rilke, $A$ Canção de Amor e de Morte do Porta-Estandarte Cristóvão Rilke, traduzida por Cecília Meireles e publicada pela Revista Acadêmica em 1947, nem por isso pode-se sustentar qualquer afinidade ou "influência", seja no plano do entrecho ou na forma, linguagem, estilo etc, mesmo que fosse com intenção irônica - ironia essa que, de todo modo, parece existir, dada a extensão do subtítulo, a referência à capital mineira e a datação inverossímil...

Uma segunda consideração diz respeito ao fato de Saraiva alinhar indiscriminadamente Drummond à geração de 45, numa suposta influência desta sobre os poetas mais velhos, seja na reabilitação do soneto, seja no rilkeanismo, pela alusão contida ao poeta austríaco em Claro enigma. Segundo o crítico, muito embora Drummond tenha chegada a "ridicularizar tal forma" em dado momento de sua trajetória, o poeta passa a praticála "numerosamente em livros dos fins de 40 e inícios de 50", por "contágio" devido à geração de 45... Ora, a realização do soneto em Claro enigma dá-se de forma muito diversa do convencionalismo dispensado por 45 a essa forma fixa (basta lembrar de "Oficina irritada"), assim como a evocação a Rilke em "Aspiração" faz-se não no sentido da adesão incondicional ao rilkeanismo, mas pela negação, reiterada ao longo das quatro quadras:

\section{Aspiração}

Já não queria a maternal adoração que afinal nos exaure, e resplandece em pânico, tampouco o sentimento de um achado precioso como o de Catarina Kippenberg aos pés de Rilke.

E não queria o amor, sob disfarces tontos da mesma ninfa desolada no seu ermo e a constante procura de sede e não de linfa, e não queria também a simples rosa do sexo, 
abscôndita, sem nexo, nas hospedarias do vento, como ainda não quero a amizade geométrica de almas que se elegeram numa seara orgulhosa, imbricamento, talvez? de carências melancólicas.

Aspiro antes à fiel indiferença

mas pausada bastante para sustentar a vida e, na sua indiscriminação de crueldade e diamante, capaz de sugerir o fim sem a injustiça dos prêmios (ANDRADE, p. 212-213).

Transitando do pretérito imperfeito, com sua sugestão de continuidade e duração, para o presente do indicativo, a referida negação estende-se a formas de relacionamento humano potencializado ao extremo, projetado a um grau de excepcionalidade e idealização que leva o eu lírico drummondiano, como sempre, a reagir com desconfiança e desmistificação. Essa reação é exacerbada em virtude do pessimismo radical que marca a lírica de Drummond no pós-guerra, cujas razões examinei em outro lugar (CAMILO, 2005).

Assim ocorre com o cansaço ou esgotamento a que leva a "maternal adoração"; e com o amor, apresentado de forma desmistificada, porque "sob disfarces tontos", e denunciado como algo que se anseia mais pela falta do que pela satisfação ("a constante procura de sede e não de linfa"). A referência à ninfa desolada mostra que o poeta pensa na representação literária convencional desse anseio maior de sofrimento do que de realização. No caso do sexo, a recusa parece se justificar por sua dimensão fugaz (porque "nas hospedarias do vento"). Por último, a amizade vista como o encontro simétrico de duas almas, orgulhosamente sustentado por aqueles que se têm como eleitos, é uma forma, segundo o eu lírico drummondiano, de mascarar as "carências melancólicas" desses pretensos seres de exceção.

Ainda na $1 \stackrel{\text { a }}{\text { estrofe }}$ - a de maior interesse aqui pela referência expressa a Rilke -, o que se nega juntamente com a "maternal adoração" é o "sentimento de um achado precioso" que a esposa de Anton Kippenberg, dono da prestigiosa casa editorial Insel-Verlag e editor de Rilke, nutriu em relação ao poeta austríaco, sobre quem, aliás, ela escreveu um estudo de referência. Quem sabe, Drummond conhecesse a tradução francesa desse estudo, que saiu, em uma edição ilustrada, em 19441. A atitude de frau Kippenberg configura, em boa medida, algo daquele fervor e convicção que marcou a atitude do leitor de Rilke, segundo de Man. É essa atitude devocional que os versos de "Aspiração" buscam, afinal, recusar. Com isso, trata-se também de uma recusa à concepção do poeta como oráculo ou ser de exceção, "curandeiro

Consultei um exemplar dessa tradução pertencente à Coleção de Antonio Candido na Biblioteca Florestan Fernandes (FFLCH/USP). da alma", conforme ainda de Man (p.38), detentor de uma verdade maior que interessa a todos e justifica a reverência e a idolatria de Catarina Kippenberg para com o poeta. Ao invés disso, o eu drummondiano aspira à "fiel indiferença [...] capaz de sugerir o fim sem a injustiça dos prêmios", atitude desenganada em relação a qualquer crença na possibilidade de reconhecimento público e de comunicação ou comunhão com o leitor, que reverbera em todo Claro enigma (cf. CAMILO, 2005).

Essa atitude de constante ou "fiel indiferença" pode ter algum eco nos escritos do próprio Rilke, que falam de uma "indiferença íntima" de Malte como reencarnação do filho pródigo (RILKE, p. 214) ou se voltam criticamente contra essa ordem de sentimento em poemas como "A morte do poeta" e a 5a elegia duinense. Drummond, todavia, segue na contramão do rilkeanismo e sua acolhida curativa que, mesmo quando põe ênfase na negatividade, é para descartar a suspeita e assegurar a veracidade daquela promessa de salvação existencial, que vimos com de Man. Em suma, essa atitude almejada por Drummond, a par de todas as negações que "Aspiração" enumera, segue na contramão dos anseios órficos, de filiação claramente rilkeana, acalentados pelos poetas de 45, na busca de prestígio e restauração dos laços com esse leitor (cf. CAMILO, 2013).

Embora óbvio, vale por último reconhecer nessa síntese da recepção traçada por Saraiva que o caso português evidentemente é uma exceção à regra ao eleger a parcela tida como mais "experimental" da obra rilkeana, representada pelos Dinggedichte. Como bem se percebe na própria leitura demaniana, a parcela que fez a fama surpreendente de Rilke e a única capaz de garantir o modo de recepção altamente pessoal de sua poesia, foi, sem dúvida, a dos poemas de substrato existencial e perquirições metafísicas. Nisso, portanto, a geração de 45 seguia a tendência dominante em diferentes literaturas.

Só para citar mais um exemplo, a vertente neoclássica da geração de 40 argentina, similar a que marcou os anos 1940 e 1950 no Brasil, também fundamentou-se em um orfismo tributário da leitura que Rilke faz do mito nessa mesma parcela de sua obra representada pelos sonetos e elegias. Ou seja, como sintetiza Víctor Gustavo Zonana, o Orfeu rilkeano celebrado por correspondente geração argentina é "o nume do canto e como tal tem a missão de redimir as coisas" ao torná-las som, levando-as no canto "a uma forma plena de existência". Redimindo "as coisas através do canto, Orfeu opera suas metamorfoses da ordem do visível à do invisível" e, neste ato, "revela-se como deus ctônico por excelência, já que cumpre com a aspiração profunda da Terra". Para cumprir tal aspiração, ele torna-se o vate que "resolve a unidade entre a vida e a morte", estabelecendo a conexão sublime entre esses dois mundos. É "o vate da totalidade, do aberto". 
Instalando-se acima de toda mudança, o canto de Orfeu expressa a vocação da permanência da terra, dignidade que alcançou pela catábase. O giro hermêutico que Rilke promove, com relação à descida de Orfeu ao reino dos mortos, "não é tanto a busca de um bem arrebatado", mas antes uma "forma de iniciação que lhe permite alcançar um saber arcano e, paralelamente, assumir a prerrogativa do cantar". Por último, Rilke opera uma recriação do sentido do despedaçamento de Orfeu, que deixa de ser produto de um combate divino, para se tornar uma "instância necessária à metamorfose do herói”, ou ainda "um sacrifício de doação por meio do qual os homens se fazem credores do magistério órfico" (ZONANA, p. 38-41). Tanto o giro hermêutico, quanto a recriação do sentido despedaçamento órficos promovidos por Rilke permeiam as reescritas do mito promovidas pela geração de 45 e pelos modernistas reclassicizados, conforme tratei de demonstrar contrastivamente no estudo de que parte o presente artigo (CAMILO, 2013).

Para concluir este breve comentário sobre a presença de Rilke no período, pode-se dizer que no próprio poeta austríaco encontra-se um parâmetro para precisar o sentido do neoclássico entre os modernistas classicizados, como Drummond, Jorge de Lima, Murilo Mendes e Augusto Meyer, entre outros, e a geração de 45. Para tanto, considere-se o que observa Judith Ryan a respeito do diálogo do poeta austríaco com a tradição clássica, mediado pela apropriação simbolista desse mesmo legado:

A forma do modernismo de Rilke é uma espécie muito particular, restauradora e elegíaca. [...] Mas, diferentemente de Valéry, Rilke não dirige seus esforços restauradores à antiguidade clássica. O elemento neoclássico que é tão decisivo em Valéry - como também em seus contemporâneos Eliot e Pound - está quase completamente desaparecido em Rilke, mesmo quando ele se dirige aos temas clássicos, como em seus poemas sobre Apolo, Orfeu e Narciso. Os textos mais classicizantes de Rilke, de fato, contam principalmente com modulações simbolistas ou esteticistas de motivos antigos. Sem as esculturas de Rodin, o orfismo de Mallarmé, o Narciso de Valéry, haveria menos lembranças da antiguidade clássica nos trabalhos de Rilke. A versão rilkeana do ensaio simbolista de Valéry sobre o arquiteto órfico dos tempos antigos produz um de seus sonetos mais contundentemente modernistas. [...] O sucesso poético de Rilke nasce de seu modo de combinar dois gestos contraditórios: de um lado, seus textos convocam o leitor a se sentir diretamente abordado; de outro, negam o acesso ao que eles implicam, um segredo impenetrável no seu coração. As estruturas apelativas mediam entre a antiga figura da apóstrofe e um desejo moderno de querer cruzar a fronteira entre arte e vida. [...] O processo de autocriação de Rilke foi, de fato, um projeto permanente de restauração. Evitando o gesto vanguardista de ruptura com o passado, Rilke reavivou elementos da tradição e recombinou-os de acordo com seus próprios métodos catalíticos. [...] Suas vozes infiltraram sua poesia, repetidamente causando a autoconstrução projetada para ser rompida. Em uma época em que se tentou, de modo muitas vezes paradoxal, controlar o ato criativo, a perda de controle foi devastadora. A divergência entre construção consciente e sua constante ameaça de colapso é o que faz de Rilke uma testemunha tão eloquente das primeiras décadas da era modernista (RYAN, p. 221-227 (ao citar, traduzi)).

É essa forma de apropriação mediada por simbolistas ou mesmo por modernos, que parece definir o teor do classicismo praticado aqui no segundo pós-guerra. E ainda que se encontre com menos frequência a combinação genial de gestos contraditórios que fez o sucesso do poeta austríaco, vemos nos mais altos momentos da produção poética do período essa divergência que, segundo a intérprete de Rilke, fez dele um testemunho eloquente da era modernista.

\section{Referências}

ANDRADE, Carlos Drummond de. Poesia e prosa. Rio de Janeiro: Nova Aguilar, 1992.

CAMILO, Vagner. Drummond: da Rosa do povo à rosa das trevas. 2. ed. São Paulo: Ateliê Editorial, 2005.

CAMILO, Vagner. A modernidade entre tapumes: da lírica social à conversão neoclássica. São Paulo: USP, 2013. (Versão revista de tese de livre-docência).

CAMPOS, Augusto de. Coisas e anjos de Rilke. São Paulo: Perspectiva, 2001.

DE MAN, Paul. "Tropos (Rilke)". Alegorias da leitura: linguagem figurativa em Rousseau, Nietzsche, Rilke e Proust. Tradução de Lenita R. Esteves. Rio de Janeiro: Imago, 1996.

FONSECA, José Paulo Moreira da. Elegia diurna. Rio de Janeiro: José Olympio Ed., 1947.

HÖRSTER, Maria; HENRIQUES, António; FERREIRA, Jorge. Para uma História da Recepção de Rainer Maria Rilke (19201960). Coimbra: Fundação Calouste Gulbenkian/Fundação para a Ciência e a Tecnologia, 2001.

KIPPENBERG, Katharina. Rainer Maria Rilke: un témoignage. Tradução de Blaise Briod. Paris: Plon, 1944.

MELO NETO, João Cabral de. "Rilke nos Novos poemas". Obra completa. Rio de Janeiro: Nova Aguilar, 1994.

MEYER, Augusto. Poesias 1922-1955. Rio de Janeiro: Livraria São José Ed., 1957.

MORAES, Vinícius de. Antologia poética. São Paulo: Companhia das Letras, 2001.

MOTA, Mauro. Elegias. Rio de Janeiro: Edições Jornal de Letras, 1952. 
PENSAMENTO E ARTE. Correio paulistano (supl.), São Paulo, 25 ago. 1951.

PIGNATARI, Décio. Poesia pois é poesia: 1950-2000. São Paulo: Ateliê Editorial; Campinas: Editora da Unicamp, 2004.

Revista Joaquim, Curitiba, n. 7 (dez. 1946) e n. 15 (nov 1947).

Revista Orfeu, Rio de Janeiro, n. 1 (primavera de 1947) e n. 3 (outono de 1948).

RILKE, Rainer Maria. Os cadernos de Malte Laurids Brigge. Tradução de Paulo Quintela. Porto: O Oiro do Dia, 1983.
RYAN, Judith. Rilke, Modernism and Poetic Tradition. Cambridge: Cambridge UP, 1999.

SARAIVA, Arnaldo. Para a história da leitura de Rilke em Portugal e no Brasil. Porto: Edições Árvore, 1984.

ZONANA, Víctor Gustavo. Orfeos argentinos. Lira del '40. Mendoza: EDIUNC, 2001.

Recebido: 14 de maio de 2017 Aprovado: 15 de maio de 2017

Contato:vcamilo@usp.br 